\title{
Factor Analysis of Paddy-Field Consolidation: Case Study of Iran
}

\author{
Ebrahimi Mohammad Sadegh ${ }^{1}$, Kalantri Khalii ${ }^{2} \&$ Asadi Ali $^{1}$ \\ ${ }^{1}$ Department of Rural Development, College of Agriculture, Isfahan University of Technology, Isfahan, Islamic \\ Republic of Iran \\ ${ }^{2}$ Department of Management and Agricultural Development, College of Agriculture, Campus of Agricultural and \\ Natural Resources, University of Tehran, Karaj, Islamic Republic of Iran \\ Correspondence: Ebrahimi Mohammad Sadegh, Department of Rural Development, College of Agriculture, \\ Isfahan University of Technology, Isfahan, Islamic Republic of Iran. E-mail: Ebrahimi_ms@cc.iut.ac.ir
}

Received: November 16, 2011 Accepted: February 28, 2012 Online Published: July 15, 2012

doi:10.5539/sar.v1n2p108 URL: http://dx.doi.org/10.5539/sar.v1n2p108

\begin{abstract}
Land consolidation is a strategy for the development of Iranian rice-growing regions. The most important targets of the program are reducing rice farmers' expenses and increasing their income. The object of this article is to conduct a factor analysis of Iranian paddy-field consolidation. The research was conducted in the form of a survey study. The data was collected from 188 farmers participating in a farm-development program in Guilan province, sampled using a stratified random sampling method. The reliability of the questionnaire was calculated using a Cronbach alpha coefficient (alpha $>0.78$ ) for different sections after conducting a pilot study. Factor analysis for farmers with rice fields in projects showed that five factors explained $63.92 \%$ of total variance. These factors were: 1) social, 2) instructional, 3) environmental, 4) economic and 5) institutional effects. Social effects alone, the factor with the greatest effect, explained $34.84 \%$ of total variance.
\end{abstract}

Keywords: land consolidation, agricultural development, paddy fields, factor analysis

\section{Introduction}

Rice is the second most important food source in Iran after wheat, particularly in northern areas (Peykani et al., 2008). Annual per-capita average usage of rice in the world is between 80 and $90 \mathrm{~kg}$. In Iran, however, the annual per-capita consumption of rice was $18.6 \mathrm{~kg}$ in 1961, rising to around $60 \mathrm{~kg}$ by 2005 (FAO, 2009). Although the production of rice has increased in recent years, the gap between domestic production and consumption of rice has fluctuated, and a substantial share of consumption is imported into Iran each year (Bakhshoodeh, 2010). Land consolidation is a strategy for the development of Iranian rice-field regions. It has led to the expansion of paddy-field size, enhancing the efficiency of large machinery, which in turn has resulted in increased productivity. The other important initiative in paddy-field improvement is the promotion of mixed land use, to enable cultivation of upland crops such as wheat and soybean and minimize the overproduction of rice. On the whole, paddy-field improvements represent an important technical and political measure to achieve sustainable development of agriculture, reconciling the demands for food production and environmental conservation (Wrachien, 2003).

\section{Conceptual Framework}

Land consolidation effects have been studied in different views in the world. Castro Coelho et al. (2001) studied a systems approach for estimating the effects of land-consolidation projects. Their results suggest the existence of synergies among the different investments usually included in such projects: in other words, they found an increase in the returns exceeding the sum of impacts from the individual changes. Their results showed that land consolidation projects have led to more rational use of land, an increase in land and labor productivity, a decrease in production costs, an increase in farmer incomes and, in more general terms, an important improvement in the rural standards of living. Land consolidation, therefore, can be an important step in promoting rural development in depressed and fragmented agricultural areas. Also Anbumozhi et al. (2001) studied sustaining agriculture through modernization of irrigation tanks. They study showed that the modernization program reduced water usage by more than $25 \%$. A pilot project showed that by physical (hardware) modernization alone, irrigation efficiency improved by $32.25 \%$, and yield increased by about $30 \%$. In addition to Kunimitsu et al. (2005) conducted a benefit-incidence analysis on the far-reaching effects of 
paddy-field consolidation projects. The results were as follows: first, certain benefits to farmers primarily derived from the projects have been transferred to consumers through declines in the price of rice. The transfer ratio was more than half of the total improvement of rice productivity for farmers, and all economic sectors including farmers and consumers - received net benefit even though all sectors paid construction costs or taxes. Second, some unexpected benefits for the rural environment were revealed on many project sites.

Sanzidur and Mizanur (2009) studied the impact of land fragmentation and resource ownership on productivity and efficiency. Results showed that, as expected, land fragmentation had a significant detrimental effect on productivity and efficiency. Also Shuhao et al. (2007) studied the question of whether fragmented landholdings have higher production costs. Their study showed that a reduction of the average distance to plots and an increase in farm size decreased total production costs per ton.

These studies give strong evidence that land consolidation programs can only contribute to the joint policy goals of increasing agricultural production capacity. Therefore in this research was investigated these factors in Iranian paddy fields and compared this result with other result research for identifed the most important factors that effect in Iranian paddy fields.

\section{Materials and Methods}

Table 1. The variables of research

\begin{tabular}{|c|c|}
\hline Variable name & $\begin{array}{l}\text { Measurement } \\
\text { scale }\end{array}$ \\
\hline $\begin{array}{l}\text { Farmers attitude towards the land consolidation } \\
\text { design }\end{array}$ & Sequential \\
\hline Satisfaction with the design & Sequential \\
\hline Being more precise about land & Sequential \\
\hline Developing teamwork & Sequential \\
\hline Participation in the project & Sequential \\
\hline Legal status of project & Sequential \\
\hline Solve the problem of land- ownership documents & Sequential \\
\hline Willingness to transfer land to other design & Sequential \\
\hline Farm drainage problem-solving & Sequential \\
\hline Farm inputs to solve transportation problems & Sequential \\
\hline Farm irrigation problem-solving & Sequential \\
\hline Solving difficult access to paddy fields & Sequential \\
\hline Prevent destruction of forests and environment & Sequential \\
\hline Prevent user to change fields & Sequential \\
\hline Damage to soil in the project & Sequential \\
\hline Yield ha & Relative \\
\hline Income ha & Relative \\
\hline Spending ha & Relative \\
\hline Better rules for better implementation plan & Sequential \\
\hline Farming land-size(ha) & $\begin{array}{l}\text { Sequential } \\
\text { Relative }\end{array}$ \\
\hline Number of plots & Sequential \\
\hline Carrying of inputs & $\begin{array}{l}\text { Sequentral } \\
\text { Seguential }\end{array}$ \\
\hline Carrying of crops & \\
\hline Harvest method (\%) & Relative \\
\hline Attitude toward project & Sequential \\
\hline Level of education & Sequential \\
\hline Age & Relative \\
\hline Use of inputs & Relative \\
\hline
\end{tabular}

This study is applied research carried out by the survey method. The data for this research was collected from 188 farmers participating in a farm-development program in Guilan province, sampled using a stratified random 
sampling method. The-questionnaire-by-interview method was used for data collection. To examine the reliability of the questionnaire a pilot test was conducted on 30rice farmers in Syahkal county. The reliability of the questionnaire was calculated using a Cronbach alpha coefficient (alpha $>0.78$ ) for different sections after conducting the pilot study. The alpha value showed that the selected scales were appropriate for measurement. Factor analysis was applied as the main statistical technique to analyze the data. The main object of this technique is to classify a large number of variables into a small number of factors based on relationships among variables. For this purpose 28 variables were selected for analysis. The variables that investigated in this research showed in Table 1. To determine the appropriateness of data and measure the homogeneity of variables attracting farmers to group activities, the Kaiser-Meyer-Olkin (KMO) and Bartlett's test measures were applied. These statistics show the extent to which the indicators of a construct belong to each other. The KMO and Bartlett's test results obtained for these variables show that the data are appropriate for factor analysis (Table 2).

Table 2. KMO measure and bartlett's test to assess appropriateness of the data for factor analysis

\begin{tabular}{ccc}
\hline \multirow{2}{*}{ KMO } & \multicolumn{2}{c}{ Bartlett's test of sphericity } \\
& Approx. chi-square & Sig. \\
\hline 0.760 & 3194.82 & 0.000 \\
\hline
\end{tabular}

Factor analysis is a statistical method that is based on the correlation analysis of multi-variables. The purpose is to reduce multiple variables to a lesser number of underlying factors that are measured by the variables. Factors are formed by grouping the variables that have a correlation with each other. Factor analysis is effective when the sample size is more than 300. There are mainly four stages in factor analysis (M. Emin et al., 2007).

a. Initial solution: Variables are selected and an inter correlation matrix is generated for including all of the variables. An inter-correlation matrix is a $\mathrm{k} \mathrm{k}$ (where $\mathrm{k}$ equals the number of variables) array of the correlation coefficients of the variables with each other. When the degree of correlation between the variables is weak, it is not feasible for these variables to have a common factor, and a correlation between these variables is not studied. Kaiser-Meyer-Olkin (KMO) and Bartlett's tests of sphericity (BTS) are then applied to the studied variables in order to validate if the remaining variables are factorable. The KMO value should be greater than 0.5 for a satisfactory factor analysis. BTS, on the other hand, should show that the correlation matrix is not an identity matrix by giving a significance value smaller than 0.001 .

b. Extracting the factors: An appropriate number of components (factors) is extracted from the correlation matrix based on the intial solution. In the initial solution, each variable is standardised to have a mean of 0.0 and a standard deviation of 71.0. Thus, the eigenvalue of the factor should be greater than or equal to 1.0 , if it is to be extracted.

c. Rotating the factors: Sometimes one or more variables may load about the same on more than one factor, making the interpretation of the factors ambiguous. Thus, factors are rotated in order to clarify the relationship between the variables and the factors. While various methods can be used for factor rotation, the Varimax method is the most commonly used one.

d. Naming the factors: Results are then derived by analysing the factor load of each variable. Appropriate names are given to each factor by considering the factor loads (M. Emin et al., 2007).

\section{Results and Discussion}

The research results showed that the average size of developed paddy field was 1.4 ha and the number of plots was 2 (Table 3). Meanwhile, the average size of Iranian paddy fields is one hectare, and the average number of plots of Iranian paddy fields is four. This result showed that the design was successful for reduce of plots number and increased of average size of paddy fields in Iran.

To investigate the factors affecting implementation, factor analysis was performed, and the variables were divided into four factors (Table 4). Among the factors, the first was social factors. This factor alone accounted for $34.83 \%$ of the total variance. The highest load factor in the operating variables related to the farmers attitudes towards land consolidation design (Table 5). 
Table 3. Developed paddy fields characteristic in Iran

\begin{tabular}{cc}
\hline Variable & Parameter \\
\hline Farming land-size(ha) & Mean:1.399, Sd:0.867 \\
Number of plots & Mode: 1 \\
& Mode: 2 \\
Carrying of inputs & Hand:\%13.3 \\
& Machine:\%86.7 \\
Carrying of crops & Machine:\%89 \\
& Hand:\%76.6 \\
Harvest method & Machine:\%24.4 \\
\hline
\end{tabular}

Table 4. Number of extracted factors, eigenvalues and variance explained by each factor

\begin{tabular}{cccc}
\hline Factors & Eigenvalue & \% of variance & Cumulative \% of variance \\
\hline 1 & 9.06 & 34.84 & 34.84 \\
2 & 2.578 & 9.917 & 44.76 \\
3 & 1.939 & 7.456 & 52.22 \\
4 & 1.821 & 7.004 & 59.22 \\
5 & 1.222 & 4.698 & 63.92 \\
\hline
\end{tabular}

Table 5. Variables loaded in the first factor using varimax rotated factor analysis

\begin{tabular}{llc}
\hline Name of factor & \multicolumn{1}{c}{ Variables loaded in the factor } & Factor loadings \\
\hline & Farmers attitude towards the land consolidation design & 0.894 \\
& Satisfaction with the design & 0.811 \\
& Being more precise about land & 0.779 \\
& Plans in accordance with the original design & 0.747 \\
Social factor & Developing teamwork & 0.747 \\
& Participation in the project & 0.720 \\
& Legal status of project & 0.701 \\
& Solve the problem of land-ownership documents & 0.700 \\
& Willingness to transfer land to other design & 0.645 \\
\hline
\end{tabular}

The second factor was the instructional factor. This factor alone accounted for $9.92 \%$ of the total variance. The instructional factor remarked the variables: farm drainage problem-solving, farm inputs to solve transportation problems, Farm irrigation problem-solving and Solving difficult access to paddy fields (Table 6).

The third factor, the environmental factor, accounted for $7.46 \%$ of the total variance. The highest load factor related to the variable factor "preventing the destruction of forests and environmental degradation" is the design (Table 7). The fourth factor, the economic factor, explained $7 \%$ of the total variance. The economical factor is remarked to reduce the cost of production and increased the yield and income of production in paddy fields (Table 8 ). The fifth factor, institutional factors, accounted for $4.7 \%$ of the variance (Table 9). The better rules for better implementation design are the variable that loaded in this factor. 
Table 6. Variables loaded in the second factor using varimax rotated factor analysis

\begin{tabular}{ccc}
\hline Name of factor & Variables loaded in the factor & Factor loadings \\
\hline \multirow{3}{*}{ Infrastructure factor } & Farm drainage problem-solving & 0.646 \\
& Farm inputs to solve transportation problems & 0.594 \\
& Farm irrigation problem-solving & 0.589 \\
& Solving difficult access to paddy fields & 0.512
\end{tabular}

Table 7. Variables loaded in the third factor using varimax rotated factor analysis

\begin{tabular}{clc}
\hline Name of factor & \multicolumn{1}{c}{ Variables loaded in the factor } & Factor loadings \\
\hline \multirow{3}{*}{ Environmental factor } & Prevent destruction of forests and environment & 0.833 \\
& Prevent user to change fields & 0.775 \\
& Damage to soil in the project & 0.724 \\
\hline
\end{tabular}

Table 8. Variables loaded in the fourth factor using varimax rotated factor analysis

\begin{tabular}{llc}
\hline Name of factor & Variables loaded in the factor & Factor loadings \\
\hline \multirow{3}{*}{ Economic factor } & Yield ha & 0.822 \\
& Income ha & 0.796 \\
& Spending ha & -0.525 \\
\hline
\end{tabular}

Table 9. Variables loaded in the fifth factor using varimax rotated factor analysis

\begin{tabular}{ccc}
\hline Name of factor & Variables loaded in the factor & Factor loadings \\
\hline Institutional factor & Better rules for better implementation plan & 0.726 \\
\hline
\end{tabular}

The results of this study showed that the land consolidation project was successful for reduce of plots number and increased of average size of paddy fields in Iran. The land consolidation effect can be summarized in five factors these factors explained $59.78 \%$ of total variance of land consolidation design in Iranian paddy felids. These factors were: 1) social, 2) instructional, 3) environmental, 4) economic and 5) institutional effects. Social effects explained $34.84 \%$ of total variance, making this the greatest factor. In this factor in the most important variable is farmer's attitude towards the land consolidation design. This result confirms research results from Ashekar et al. (2004), Asadi et al. (2003) and Niroula and Thapa (2005) concerning social problems in the implementation of land-development plans. Therefore, one key to success in solving social problems is to program.

The second factor, managing infrastructure, accounted for $9.29 \%$ of the total variance. In this factor solve the paddy fields daring problem is a basic variable because this fields don't have suitable daring condition. These results confirm studies by Sundqvist and Anderson (2007), Tabuchi (2004) and Marsh and Gordon (2006) regarding the problems of access to paddy fields.

The third factor, environment, accounted for $7.4 \%$ of the total variance. In this factor in the most important variable is preventing the destruction of forests and environment. These results confirm research by Rzavipour (2004) and Tenkanen (1994).

The fourth factor, economic factors, accounted for $7 \%$ of the total variance. The amount of production per hectare has the maximum eignvalue in this factor because the land consolidation design could provide higher production in paddy fields. These results confirm research by Fotouhi (2005); Castro, Coelho, Pinto and Dasilva (2001); Anbumozhi, Matsumoto and Yamaji (2002); Fukuda, Duck and Stout (2003); Luers, Naylor and Matson (2005); Atsushi (2002); Marsh and Gordon (2006); Bullard (2007); and Sundqvist and Anderson (2007). 
The fifth factor, institutional factors, accounted for $4.7 \%$ of total variance. The need of the better rules for the design has the maximum eigenvalue in this factor. In other whole land consolidation design need the better rules for do better effective successfully.

\section{Conclusion}

The land consolidation effect can be summarized in five factors: 1) social, 2) instructional, 3) environmental, 4) economic and 5) institutional effects. The most important factor for Iranian paddy fields was social factors and the highest load factor in the operating variables related to the farmers attitudes towards land consolidation design. Therefore, one key to success in solving social problems is to program. Also solve the paddy fields daring problem is a basic variable because this fields don't have suitable daring condition. In addition to the land consolidation project could be preventing the destruction of forests and environment. Also the land consolidation design could provide higher production in paddy fields. Also for the correct of land consolidation project process suggest this project need of the better rules. In other whole land consolidation design need the better rules for do better effective successfully. Therefore, more attention to the facilitator operating activities should promote the cause and what the appropriate training before and during project implementation be carefully.

\section{Acknowledgment}

This study was based on a research project financially supported by university of Tehran, Iran, which the authors greatly appreciate.

\section{Reference}

Anbumozhi, V., Matsumoto, K., \& Yamaji, E. (2002). Sustaining Agriculture through Modernization of Irrigation Tanks: An Opportunity and Challenge for Tamilnadu, India. Agricultural Engineering International: the CIGR Journal of Scientific Research and Development, 3, 11-18.

Asadi, R., Yazdani, M., Parsi, R., \& Nezhad, M. (2006). Study of irrigation and drainage channels in land-consolidation projects in rice fields. Rice Research Institute of Iran - RRII. Amol (Iran).

Bakhshoodeh, M. (2010). Impacts of world prices transmission to domestic rice markets in rural Iran. The Journal of Food Policy, 35(1), 12-19. http://dx.doi.org/10.1016/j.foodpol.2009.06.006

Castro Coelho, J., Aguiar, P., \& Mira da Silva, L. (2001). A systems approach for the estimation of the effects of land consolidation projects (LCPs): a model and its application. Agricultural Systems, 68(3), 179-195. http://dx.doi.org/10.1016/S0308-521X(00)00061-5

FAO. (2009). Faostat. Rice. Islamic Republic of Iran.

Kunimitsu, Y., Nakata, S., \& Toshima, R. (2005). A benefit incidence analysis on the far-reaching effects of paddy-field consolidation projects. Paddy and Water Environment, 3(2), 127-134. http://dx.doi.org/10.1007/s10333-005-0004-8

Kunimitsu, Y. (1999). A cost-benefit analysis on the paddy-field consolidation projects (in Japanese). Trans. Japan: Social Irrigation, Drain Reclaim Eng, 204, 39-46.

Kunimitsu, Y. (2005). Impacts of paddy-field consolidation projects on farmland rental transactions: application of discrete choice model. Japan: Journal of Rural Economics, 7, 49-60.

Emin, M. O., Emel, L. O., Ercan, E., \& Gamze, V. (2007). Industry financial ratios-application of factor analysis in Turkish construction industry. Building and Environment, 42, 385-392. http://dx.doi.org/10.1016/j.buildenv.2005.07.023

Peykani, G. R., Kavoosi, M., Sadat, H., \& Sasouli, M. R. (2008). Comparison of Production Productivity of Three Rice Varieties Including Long Grain Good Quality, Long Grain High Yielding and Hybrid Rice in Iran.Case Study: Guilan Province. American-Eurasian Journal of Agricultural and Environmental Science. 4(5), 625-632.

Sanzidur, R., \& Mizanur, R. (2009). Impact of land fragmentation and resource ownership on productivity and efficiency: The case of rice producers in Bangladesh. The Journal of Land Use Policy, 26(1), 95-103. http://dx.doi.org/10.1016/j.landusepol.2008.01.003

Shuhao, T., Nico, H., Gideon, K., \& Futian, Q. (2007). Do fragmented landholdings have higher production costs? Evidence from rice farmers in Northeastern Jiangxi province, P. R. China. The Journal of China Economic Review, 19(3), 347-358. 
Wrachien, D. (2003). Paddy and Water Environment: Facilitation information exchange and identifying future R \& D needs. Journal of Paddy and Water Environment, 3-5.

Yazdani, M. R., Razavi, Pour, T., Sha`bani. M., \& Parsi Nezhad, M. (2005). Evaluation of inter field road and installation in land consolidation projects in Guilan province. Rice Research Institute of Iran. Rasht (Iran).

Yazdani, M. R. (2005). Evaluation of Irrigation and Drainage canals in land consolidation projects in Guilan. Rice Research Institute of Iran. Rasht (Iran). 